AC 2008-1830: STUDENTS' PERCEPTIONS OF THE IMPORTANCE OF FACULTY TECHNICAL CURRENCY, TEACHING TECHNIQUES, AND COMMITMENT TO STUDENT SUCCESS FOR THEIR LEARNING/ SUCCESS

\author{
Ahmed Khan, DeVry University \\ Gene Gloeckner, Colorado State University \\ George Morgan, Colorado State University
}




\title{
STUDENTS' PERCEPTIONS OF THE IMPORTANCE OF
}

\author{
FACULTY TECHNICAL CURRENCY, TEACHING TECHNIQUES, \\ AND COMMITMENT TO STUDENT SUCCESS FOR THEIR
}

\author{
LEARNING/ SUCCESS
}

\begin{abstract}
The paper presents the results of a study that explored the relationships between students' perceptions of the importance of three faculty dimensions --- technical currency, teaching techniques, and commitment to student success --- to their learning/success, expressed in terms of self-reported technical competencies and GPA in a technology-based baccalaureate electronics engineering technology (EET) program at a teaching university. The sample $(\mathrm{N}=225)$ was composed of seniors of the BSEET program from 13 geographically diverse campuses of a teaching university. More than $75 \%$ of the EET seniors agreed that the constructs of faculty technical currency, teaching techniques, and commitment to student success, are important to their learning/success.
\end{abstract}

Regression analyses revealed significant and direct relationships between: (a) faculty technical currency (FTC) and student learning/success in terms of self reported technical competency (effect size is medium), (b) faculty teaching techniques (FTT) and student learning/success in terms of self reported technical competency (effect size is medium-tolarge), (c) faculty commitment to student success (FCSS) and student learning/success in terms of self-reported technical competency (effect size is medium), (d) faculty technical currency (FTC) and faculty teaching techniques (FTT) [large effect size], and, (e) faculty technical currency (FTC) and faculty commitment to student success (FCSS) [effect size is large]. An effect size is a quantitative indicator used in correlational studies to signify the statistical significance regarding the strength of the relationship between the independent variable and the dependent variable. It indicates how much variance in the dependent variable can be predicted from the independent variable.(Effect size scale used for the study: small $(\mathrm{s})=0.1-0.15$, small-medium $(\mathrm{sm})=0.151-0.249$, medium $(\mathrm{m})=$ $0.25-0.35$, medium-large $(\mathrm{ml})=0.351-0.449$, large $(\mathrm{l}) \geq 0.45)$. The recommendations based on the study suggest ways to improve faculty development and training activities to promote student learning in the domains of engineering technology. 


\section{Introduction}

Rapid technological growth has put new demands on engineering and engineering technology educators. Industry seeks graduates with up-to-date technical knowledge. The half-life of an engineer's technical skills - how long it takes for half of everything an engineer knows about the field to become obsolete - is becoming strikingly short [1]. The pace of technological change has also imposed new challenges on faculty development and technical currency of programs.

Faculty professional development activities and technical currency play an important role in promoting student learning and success. Especially for non-research (purely teaching) institutions that offer technology driven programs, one of the most important factors determining student success is the technical currency of faculty members [2].

Predicting the success of students engaged in higher education is important. Many models have been developed to predict student success in chosen fields of study, as well as at the chosen college or university. Success in education has been linked to a variety of intellectual and non-cognitive skills [3-11].

Researchers at various private and public research universities historically have used traditional student predictor variables (GPA, retention rate, and graduation rate) to predict student success. Even for non-research (purely teaching) schools that offer technology driven programs, one of the most important factors determining student success would seem to be the technical currency of faculty members. The accreditation bodies such as Accreditation Board for Engineering and Technology (ABET) place high emphasis on the technical currency of faculty, and require institutions to provide opportunities for faculty to keep abreast of the pace of technological advances. ABET's 2003-2004 criteria for accrediting engineering technology programs state [12]:

In engineering technology programs, technical currency is important and must be assured by such means as a competent and inquisitive faculty, an active industrial advisory committee, and an adequately funded budget which encourages continuing faculty development, and a modern library collection with an adequately funded program for continuous renewal. Positive procedures must be established and closely monitored to safeguard against technical obsolescence (p. 5).

Accreditation bodies have placed high emphasis on technical currency of faculty in the technology based programs, but the subject has received little attention in the literature. Further, no studies have been conducted to investigate the associations between the faculty dimensions of faculty technical currency, faculty teaching techniques, and faculty commitment to student success, and self-reported student learning and success. Faculty professional development activities and technical currency play an important role in promoting student learning and success. Therefore, an investigation is warranted to explore the relationship between student learning/success with these faculty constructs. 


\section{Purpose of the Study}

The purpose of this research project was to explore the relationship between students' perceptions of the importance of three faculty dimensions - technical currency, teaching techniques, and commitment to student success - and their self-reported learning and success. The research project answers the following questions:

1. How do students perceive the importance of three faculty dimensions technical currency, teaching techniques, and commitment to student success, for their learning and success? (Are means high or low?)

2. Are there associations between students' perception of the importance of faculty members' technical currency (in terms of up-to-date technical knowledge of subject matter, computer hardware and software skills, knowledge of new and emerging technologies, publication of technical papers and textbooks, and, participation in technical seminars, workshops and conferences, and professional organization activities) and students' selfreported learning/success (expressed in terms of self-reported technical competency and GPA) as perceived by seniors in the EET program?

3. Are there associations between students' perception of the importance of the faculty teaching techniques [in terms of lectures, use of a variety of technological teaching tools, use of PowerPoint, use of a variety of teaching strategies, coordinating laboratory work with lecture, organization and preparation of class/laboratory activities, use of group presentations, use of individual laboratory projects, and providing timely feedback on class/laboratory projects] and student's self-reported success/learning (expressed in terms of self-reported technical competency and GPA), as perceived by seniors in the EET program?

4. Are there associations between students' perception of the importance of faculty commitment to student success [in terms of dedication to students, high expectations of students, being approachable by students, encouraging student accomplishment, and concern for student success] and student's selfreported success/learning (expressed in terms of self-reported technical competency, and GPA), as perceived by seniors in the EET program?

5. Is there a combination of the factors of faculty technical currency (FTC), faculty teaching techniques, and faculty commitment to student success, that predict self-reported student learning/success better than one alone, as perceived by seniors in the EET program?

The proposed study used a quantitative paradigm. The associational research approach was used to study the relationship between independent variables and dependent variables. (See Table I) 
Table I

Description of Variables

\section{Variable Type}

\section{Independent Variables}

Student perceptions of the importance of:

1. Faculty Technical currency

2. Faculty Teaching Techniques

3. Faculty Commitment to Student Success

\section{Variable Description}

Faculty technical currency construct is expressed in terms of the following;

- Technical competency/technological knowledge/skills in the subject matter (up-todate technical knowledge)

- Computer hardware skills

- Computer software skills

- Knowledge of new and emerging technologies

- Publications of technical papers and textbooks

- Participation in technical seminars, workshops $\&$ conferences, and professional organization activities.

Faculty teaching techniques construct is expressed in terms of following factors:

- Lectures

- Use of a variety of technological teaching tools

- Use of PowerPoint

- Use of a variety of teaching strategies

- Use of group presentations

- Coordinating laboratory work with theoretical concepts covered in lecture

- Organizing and preparing of class and laboratory activities

- Use of individual laboratory projects

- Providing timely feedback on class and laboratory projects

Faculty commitment to student success construct is represented by:

- Dedication to students

- Requiring high expectations

- Being approachable

- Encouraging student accomplishments

- Concern for student success 


\section{Dependent Variables}

Students' perception of their learning / success in terms of:

1. GPA

2. Self-reported technical competency (SRTC1) [Critical Thinking]

3. Self-reported technical competency (SRTC2) [Job Preparation]

4. Self-reported technical competency (SRTC3) [Construction of a Prototype]
Student learning / success measured is terms of:

- GPA

- $\quad$ Self-reported technical competency (SRTC) [in terms of analytical and critical thinking, knowledge of EET, and design and implementation of a system]

- Given a technical challenge, a student can analyze a problem by thinking critically (SRTC1 [Critical Thinking])

- Student has confidence in his/her technical knowledge to be successful as an electronics engineering technology (EET) job (SRTC2) [Job Preparation]

- Given a technical problem or specification for a system design, a student can propose a solution by designing the necessary subsystem/circuits and by constructing a prototype of the system (SRTC3) [Construction of a prototype]

- Number of job offers

- Starting salary offer

- Professional /honor society membership

\section{Definitions of Terms}

For the purpose of this study, the following definitions of terms were used.

Faculty Technical Currency (FTC): Technical currency of faculty is expressed in terms of technical competency /up-to-date technical knowledge of the subject matter, computer hardware and software skills, publication of technical papers and textbooks, participation in technical seminars, workshops, conferences, and professional organization activities.

Faculty Teaching Techniques (FTT): This consists of lectures, use of a variety of technological tools to support lectures, use of PowerPoint to deliver lectures, use of a variety of teaching strategies, use of group presentations, coordinating lab work with theoretical concepts covered in class, use of individual lab projects, and providing timely feedback on class and lab projects.

Faculty Commitment to Student Success (FCSS): This refers to a faculty member's dedication to students, high expectations of students, being approachable by students, encouraging student accomplishment, and concern for student success. 
Student learning/success: It is expressed in terms of self-reported technical competency, GPA, number of job offers, highest starting salary, and membership in professional and honor societies.

\section{Delimitations}

This study is delimited to faculty members who teach technical courses in the electrical and electronics technology (EET) program at DeVry University, a private, for profit, teaching institution. Thus the results of the study are limited to purely teaching institutions and may not generalize to research universities.

\section{Assumptions and Limitations}

For this study some of the assumptions and limitations are:

1. Student success can be measured in terms of student's self-reported technical competency, GPA, number of job offers, highest starting salary, and membership in professional and honor societies.

2. A medium sample size of 200-300 will be adequate to detect relationships.

3. A convenience sampling technique will be adequate.

4. Results will be based on graduating seniors' self-reports of their learning/success rather than the use of an achievement test scores or actual later success.

5. Students will know and answer honestly about the importance of the faculty dimensions.

6. Students will understand the concept of faculty technical currency.

\section{Description of Sample and Sampling Design}

\section{Sampling}

Considering the time and cost limitations, a convenience sampling approach was employed.

\section{Participants}

The study investigated seniors, through a survey, in the BSEET program for the Fall 2003 term at 13 DeVry University campuses spread all over the country. These campuses were chosen to incorporate diversity of study population and diversity of geographic locations. The sample size was 225 seniors, and the response rate was in the range of $29 \%-100 \%$ for all 13 campuses. The survey sought descriptive information about the student perceptions about the importance of several faculty characteristics for their learning. 


\section{Instrument}

The survey instrument (Appendix A) sought descriptive information about the students' perceptions of the importance of faculty technical currency faculty teaching techniques, and faculty commitment to student success (FCSS) for their learning/success expressed in terms of 3 areas of self-reported technical competency and GPA. The survey also asked students to provide information about gender, age, ethnicity, membership in professional/honor societies, and number of hours of work/week (if they were working presently). The instrument used twenty 7-point Likert scales to collect data about student perceptions of their faculty.

\section{Validity and Reliability of Measures}

The content validity of the instrument (the degree to which the survey matches theoretical constructs of measurement for faculty technical currency, faculty teaching techniques and faculty commitment to student success was established using feedback from the dissertation committee and selected engineering technology (ET) subject experts who are members of American Society of Engineering Education (ASEE). To measure the internal consistency reliability, a pilot study was conducted at DeVry University, Addison, Illinois; Cronbach's coefficient alpha was calculated for the three faculty constructs $(\alpha=0.60,0.68,0.78)$. The statistical software package SPSS was employed to analyze the data collected from the respondents of the survey.

\section{SUMMARY OF RESULTS}

Table II presents a summary of results for students' perceptions of the importance of three faculty constructs for their self-reported learning/success. The highest level of agreement (90 percent or more) is revealed by four faculty sub-constructs: coordinating laboratory works with lectures, up-to-date technical knowledge, organization and preparation for class and laboratory activities, and professors' lectures. Note that one of the faculty technical currency and three of faculty teaching techniques, but none of the faculty commitment to student success items were among the sub-constructs that 90 percent or more of the students agreed were important for their learning/success.

\section{Table II}

Summary of Results: Highest and Lowest Levels of Agreement for Students' Perceptions of the Importance of The Faculty Constructs of Technical Currency, Teaching Techniques, and Commitment to Student Success.

\begin{tabular}{lccc}
\hline Sub-construct (Construct) & Agree & Mean & $\begin{array}{c}\text { Standard } \\
\text { Deviation }\end{array}$ \\
\hline & Highest Level of Agreement $(\geq 90 \%)$ & \\
Coordinating laboratory work with lecture & $91.9 \%$ & 6.10 & 1.16 \\
\hline
\end{tabular}


(FTT)

Up-to-date technical knowledge (FTC)

\begin{tabular}{llcc} 
& $91.4 \%$ & 5.90 & 1.16 \\
$\begin{array}{l}\text { Organization and preparation for class and } \\
\text { laboratory activities (FTT) }\end{array}$ & $91.2 \%$ & 5.99 & 1.15 \\
Professors' lectures (FTT) & $90 \%$ & 5.90 & 1.12 \\
\hline
\end{tabular}

Lowest level of Agreement $(\leq 60)$

\begin{tabular}{lccc}
$\begin{array}{l}\text { Participation in technical seminars } \\
\text { /professional societies activities (FTC) }\end{array}$ & $57.4 \%$ & 4.75 & 1.48 \\
$\begin{array}{l}\text { Publications/ technical papers/textbooks } \\
\text { (FTC) }\end{array}$ & $51.1 \%$ & 4.44 & 1.66 \\
Use of group presentations (FTT) & $49.7 \%$ & 4.39 & 1.55 \\
Use of PowerPoint (FTT) & $32.1 \%$ & 3.60 & 1.68 \\
\hline
\end{tabular}

And the lowest level of agreement (60 percent or less) is revealed by the faculty sub-constructs of participation in technical seminars /professional activities, publications/ technical papers/textbooks, use of group presentations, and use of PowerPoint. It is a very interesting to note that out of 20 faculty sub-constructs, "how PowerPoint is used by the faculty", had the lowest level of agreement. This is especially surprising when one considers how often PowerPoint is used in academia for onsite and online (web based or web supported) classes whether for synchronous or asynchronous delivery modes.

Table III presents a summary of strongest relationships ( $\mathrm{r} \geq .30)$ between students' perceptions of the importance of faculty technical currency, faculty teaching techniques, and faculty commitment to student success and students' perceptions of learning/success expressed in terms of their self-reported technical competency.

The first dependent variable, critical thinking has two relationships of $r \geq 0.30$ with the independent variables: use of individual laboratory project of the summated faculty teaching techniques. The second dependent variable, job preparation, also has two relationships of $r \geq 0.30$ with the independent variables: summated faculty teaching techniques, and summated faculty commitment to student success. The third dependent variable, construction of a prototype has six relationships of $r \geq 0.30$ with the independent variables: computer software skills, use of individual laboratory projects, timely feedback on class and laboratory projects, summated faculty teaching techniques, high expectation of students, and summated faculty commitment to student success. And, the fourth dependent variable, summated self reported technical competency, which is 
the sum of critical thinking, job preparation and construction of a prototype, has seven relationships of $r \geq 0.30$ with the independent variables, two with faculty technical currency constructs, two with faculty teaching techniques constructs, and three with faculty commitment to student success constructs. Only 1 relationship, out of 92 possible relationships between four dependent variables and 23 independent variables, was not statistically significant.

\section{Table III}

Summary of Results: Pearson Correlation Coefficients for the Relationship Between Students' Perceptions of the Importance of Faculty Technical Currency (FTC), Faculty Teaching Techniques (FTT), and Faculty Commitment to Student Success (FCSS) and Students' Perceptions of Learning/Success Expressed in Terms of Their Self-reported Technical Competency $(N=225)$

\begin{tabular}{|c|c|c|c|c|}
\hline \multirow[t]{2}{*}{$\begin{array}{l}\text { Faculty Sub-Construct } \\
\text { (Construct) }\end{array}$} & $\begin{array}{l}\text { Self-reported } \\
\text { technical } \\
\text { competency } \\
\text { (SRTC1) }\end{array}$ & $\begin{array}{l}\text { Self-reported } \\
\text { technical } \\
\text { competency } \\
\text { (SRTC2) }\end{array}$ & $\begin{array}{c}\text { Self-reported } \\
\text { technical } \\
\text { competency } \\
\text { (SRTC3) }\end{array}$ & $\begin{array}{l}\text { Summated } \\
\text { SRTC }\end{array}$ \\
\hline & $\begin{array}{c}\text { [Critical } \\
\text { Thinking] }\end{array}$ & $\begin{array}{c}{[\text { Job }} \\
\text { Preparation] }\end{array}$ & $\begin{array}{l}\text { [Construction } \\
\text { of a Prototype] }\end{array}$ & \\
\hline \multicolumn{5}{|l|}{$\begin{array}{l}\text { Statistically Most Significant } \\
\text { Relationships }(\mathrm{r} \geq .30)\end{array}$} \\
\hline $\begin{array}{l}\text { Computer software skills } \\
\text { (FTC) }\end{array}$ & - & - & 0.31 & 0.30 \\
\hline Summated FTC construct & - & - & - & 0.30 \\
\hline $\begin{array}{l}\text { Use of individual laboratory } \\
\text { projects (FTT) }\end{array}$ & 0.30 & - & 0.34 & 0.35 \\
\hline $\begin{array}{l}\text { Timely Feedback on class and } \\
\text { laboratory projects (FTT) }\end{array}$ & - & - & 0.32 & - \\
\hline Summated FTT & 0.30 & 0.32 & 0.37 & 0.38 \\
\hline $\begin{array}{l}\text { High expectations of students } \\
\text { (FCSS) }\end{array}$ & - & - & 0.31 & 0.32 \\
\hline $\begin{array}{l}\text { Concern for student success } \\
\text { (FCSS) }\end{array}$ & - & - & & 0.30 \\
\hline Summated FCSS & - & 0.30 & 0.31 & 0.34 \\
\hline $\begin{array}{l}\text { Total (No. of Statistically } \\
\text { Significant Relationship) }\end{array}$ & 2 & 2 & 6 & 7 \\
\hline
\end{tabular}

Note: For all listed correlations $p<0.001$ and the effect size is medium.

An effect size is used to indicate the strength of the relationship between the independent variable and the dependent variable. Effect size scale: small $(\mathrm{s})=0.1-0.15$, small-medium $(\mathrm{sm})=0.151-0.249$, medium $(\mathrm{m})=0.25-0.35$, medium-large $(\mathrm{ml})=0.351-0.449$, large $(\mathrm{l}) \geq 0.45$ 
SRTC1: Given a technical challenge, a student can analyze a problem by thinking critically.

SRTC2: Student has confidence in his/her technical knowledge to be successful at an electronics engineering technology (EET) job.

SRTC3: Given a technical problem or specification for a system design, a student can propose a solution by designing the necessary sub-system/circuits and by constructing a prototype of the system.

Table IV lists the Pearson correlation coefficients for the two highest relationships between the students' perceptions of the importance of the faculty dimensions of technical currency, teaching techniques, and commitment to student success and students' perception of learning/success expressed in terms of GPA. Out of 23 possible relationships between the dependent variable, GPA, and the 23 independent variables, only two relationships can be classified as having an effect size of at least small to medium $(r \geq 0.151)$.

\section{Table IV}

Summary of Results: Pearson Correlation Coefficients for the Relationship Between Students' Perceptions of the Importance of Faculty Technical Currency (FTC), Faculty Teaching techniques (FTT), and Faculty Commitment to Student Success (FCSS) and Students' Perceptions of Learning/Success Expressed in Terms of Their Self-reported GPA $(N=225)$

\section{Faculty Sub-Construct (Construct) $\quad$ GPA}

Significant Relationships

Publications/technical papers/text books (FTC)

Use of group presentations (FTT)

$-0.17$

Note: Both correlations are statistically significant at $p<.01$, and the effect size is small-to-medium An effect size is used to indicate the strength of the relationship between the independent variable and the dependent variable. Effect size scale: small $(s)=0.1-0.15$, small-medium $(\mathrm{sm})=0.151-0.249$, medium $(\mathrm{m})=0.25-0.35$, medium-large $(\mathrm{ml})=0.351-0.449$, large $(1) \geq 0.45$

The first relationship is between faculty publications/technical papers/text books and student learning/success in terms of GPA. For this relationship, the negative sign indicates that it is an inverse relationship; i.e., this indicates that students perceive that faculty technical currency in terms of publications is inversely related to their learning/success. This also suggests that students who rated faculty publications as important for their learning/success, had relatively low GPAs and vice versa. The second relationship is between faculty use of group presentations and student learning/success in terms of GPA. In this relationship, the Pearson correlation coefficient's direction is negative, which suggests again an inverse relationship. The EET seniors who considered faculty use of group presentations as an important factor for their learning/success had lower GPAs and vice versa.

In summary, based on the data, it can be concluded that, the student self-reported GPA was not a strong predictor of student success, as it failed to show any associations with self-reported student learning/success that had even a medium effect size. Six 
relationships out of 23 are statistically significant. Five out of these six are negative and only one is positive.

\section{Discussion of the Findings}

Question 1: How do students perceive the importance of three faculty dimensions - technical currency, teaching techniques, commitment to student success for their learning and success? (Are means high or low?)

\section{Faculty Technical Currency}

The analyses revealed that EET seniors perceive that the technical currency of faculty is important for their learning and success, as more than 80 percent of 225 EET seniors agreed that up-to-date technical knowledge, computer hardware and computer software skills, and knowledge of new and emerging technologies are important for their learning and success.

These results are significant when looked in light of the faculty technical currency study conducted by Khan et al. [2]. The study reported that more then 95 percent of faculty members surveyed agreed that technical currency of faculty is essential to make student learning more relevant. Further, 78 percent agreed that there exists a strong relationship between technical currency and student learning. The survey also revealed that only 26 percent of faculty members said that they have high-level skills in computer competency /IT/hardware area, and 49 percent reported that they have medium level skills in the software area.

But only half of the EET seniors agreed that the faculty publications of technical papers and textbooks, and participation in technical seminar/professional societies activities are important to their learning/success. This low rate of agreement compared to other faculty technical constructs may be due to the fact that most students may not be aware of the role and process of publications and attending technical seminars/conferences and participating in the professional organization activities in the overall professional development of the faculty.

\section{Faculty Teaching Techniques}

The analyses also revealed that the EET seniors consider that faculty teaching techniques is also important for their learning and success. About 80 percent agreed that a faculty pedagogical approach that incorporates use of a variety of teaching tools, use of a variety of teaching strategies, use of individual laboratory projects and timely feedback is important to their learning and success.

These results support Guskey's [13] findings that the teaching behavior of effective teachers incorporates providing regular and specific feedback to students about their learning. The results also agree with the recommendations (use of active learning 
techniques, providing feedback) made by Chickering and Gasmson [14] for effective undergraduate education.

More than 90 percent of seniors agreed that professor's lectures, coordinating laboratory work with lecture, and organization and preparation for class and laboratory activities, are important for their learning and success. These results support the findings reported by Guskey regarding the importance of planning and organization. The majority of EET seniors perceive that coordinating laboratory work with lecture is important for their learning. When a faculty member tries to coordinate laboratory with class, students see the application of technical theory and develop a clear understating of how to implement laboratory experiments/projects. This result appears to support one of Knowles [15] fundamental assumptions about instruction for adults: "Adults learn best when the subject content is clear and of immediate importance."

Only half of the respondents considered the use of group presentations important for their learning/success, and 42 percent disagreed with the importance of the use of PowerPoint for their learning and success. It appears that the majority of students perceive the use of PowerPoint as not important for their learning. This may be due to the fact that many faculty members just read their PowerPoint slides, making the presentation a monotonous and passive rather than an interactive exercise. So faculty members need to learn how to make PowerPoint presentations effective and interesting for students.

Out of 225 respondents, about 80 percent agreed that a faculty teaching approach which incorporates the use of a variety of teaching tools, use of a variety of teaching strategies, use of individual laboratory projects and timely feedback, is important to their learning and success.

These results support Guskey's [13] findings where he reported that the teaching behavior of effective teachers incorporates planning and organization, student participation, feedback about learning. The results also support the recommendations made by Caine and Caine [16] that teachers should incorporate a variety of experimental learning strategies in order to promote learning.

The students perceive that faculty teaching techniques is important for their learning/success. The importance of faculty pedagogy is also highlighted by considering the survey results reported by of Khan et al. [2]. Out of 226 faculty members surveyed, teaching in various technology-based programs all over the country, 47.3 percent said that they did not receive any training in the pedagogy. Therefore, there is a need for improving faculty pedagogy.

\section{Faculty Commitment to Student Success}

The study revealed that EET seniors perceive that faculty commitment to student success is important for their learning and success. About 80 percent of seniors agreed that the faculty commitment dimensions of dedication to students, being approachable, providing encouragement towards student accomplishment are important to their success 
and learning. Further, more than 75 percent of seniors agreed that professor's high expectations and concern for student success are important for their learning/success.

These results support Guskey's [13] findings about the teaching behavior of effective teachers. Guskey found that effective teachers have a positive regard for students and encourage student participation.

\section{Association Between the Students' Perceptions of the Importance of Faculty Technical Currency and Self-reported Learning/Success}

Question 2: Are there associations between students' perceptions of the importance of faculty members' technical currency (in terms of up-to-date technical knowledge of subject matter, computer hardware and software skills, knowledge of new and emerging technologies, publication of technical papers and textbooks, and, participation in technical seminars, workshops and conferences, and professional organization activities) and student's self-reported learning/success (expressed in terms of self-reported technical competency and GPA) as perceived by seniors in the EET program?

The results indicate that the EET seniors perceive that there is a direct relationship between the faculty technical currency and the first indicator of student learning/success (students' self-reported technical competency variable, SRTC1 [Critical thinking]); all Pearson coefficient $(r)$ values show small-to-medium effect sizes $(r=0.19-0.25)$, except for the summated FTC construct, where the correlation coefficient value $(0.29)$ reveals a medium effect size.

For the relationship between faculty technical currency and the second indicator of student learning/success (students' self-reported technical competency variable, [Job preparation]), Pearson coefficient values are positive (direct relationship) but mostly indicate small to medium effect sizes $(r=0.11-0.23)$.

For the relationship between faculty technical currency and the third indicator of student learning/success (students' self-reported technical competency variable, [Construction of a prototype]), all correlation coefficient values are also positive but fall in the small effect size range, except for computer software skills, and summated faculty technical currency, where the values $(0.31 \& 0.29)$ are in the medium effect size range $(r$ $=0.3$ ).

For relationships between summated self-reported technical competency and computer software skills, and summated technical currency, the correlation coefficients exhibit a medium effect size.

As for the relationship between faculty technical currency and the fourth indicator of student learning and success, GPA, most Pearson coefficient (r) values are negative (inverse relationship) but are not significant, except for the relationship between faculty publications and student GPA, for which effect size falls in the small-to-medium range ( $r$ $=-0.21$ ). This result indicates that students perceive that faculty technical currency, in 
terms of publications, is inversely related to their learning/success measured in terms of GPA. The students who rated faculty publications as an important factor for their learning/success had low GPAs and vice versa. Likewise there is an inverse relationship between the summated faculty technical currency and GPA.

It is surprising to discover that GPA did not seem to be a viable indicator of student success. This result may be due to the fact that the figures used for GPA were self-reported by the students, so there is possibility of these numbers not being accurate and rather inflated, especially by students with lower actual GPAs. The average GPA reported was 3.2 .

As there is little information available in the literature about technical currency and its relationship to student learning/success, no comparisons can be made with the literature. However the results reveal that the EET seniors perceive that each subconstruct of faculty technical currency (in terms of in terms of up-to-date technical knowledge of subject matter, computer hardware and software skills, knowledge of new and emerging technologies, publication of technical papers and textbooks, and, participation in technical seminars, workshops and conferences, and professional organization activities) is important for their learning/success, though effect size varies from small to medium for the sub-constructs. The association between summated faculty technical currency and summated student self-reported technical competency is significant and effect size is medium $(r=0.30)$. This result suggests that students are aware of the pace of technological change and they perceive that faculty who are technically current have more influence on their learning and success.

\section{Association Between the Students' Perceptions of the Importance of Faculty Teaching Techniques and Self-reported Learning/Success}

Question 3: Are there associations between students' perceptions of the importance of the faculty teaching techniques [in terms of lectures, use of a variety of technological teaching tools, use of PowerPoint, use of a variety of teaching strategies, coordinating laboratory work with lecture, organization and preparation of class/laboratory activities, use of group presentations, use of individual laboratory projects, and providing timely feedback on class/laboratory projects] and student's selfreported success/learning (expressed in terms of self-reported technical competency, and GPA), as perceived by seniors in the EET program?

The Pearson correlational coefficients for the relationship between faculty teaching techniques and students' perceptions of learning/success expressed in terms of their self-reported technical competency revealed small to medium effect sizes. The following relationships between the FTT sub-constructs and students' self-reported technical competency reveal significant associations of $r \geq 0.30$, which are medium sized effects according to Cohen (1988).

1. Use of laboratory projects and summated FTT are related to self-reported technical competency Critical thinking]). 
2. Summated FTT is related to self-reported technical competency Job preparation]).

3. Use of individual laboratory projects and timely feedback on laboratory and class projects, and summated FTT are related to self-reported technical competency [Construction of a prototype]).

4. Use of individual laboratory projects and summated FTT are related to summated self-reported technical competency.

The results suggest that students perceive that the use of individual laboratory projects, has a significant impact on student learning/success. Designing and implementing a laboratory project is an example of active learning. This finding supports one of Chickering and Gamson's [14] principles of effective undergraduate learning, which states, "Effective teaching uses active learning techniques." A laboratory project is an example of active learning, brain-compatible or constructivist learning, thus involving an application of different levels of Bloom's taxonomy [18].

The results also indicate that students perceive that professors' timely feedback on laboratory and class projects is important for their learning/success. This finding supports the results of Guskey's [13] study that providing feedback to students about their learning promotes learning.

Again it was surprising to note that the fourth predictor of student learning/success, GPA was not a viable predictor of student learning/success. For GPA, the correlation coefficient values are very small for all sub-constructs, except for use of a variety of technological tools and use of group presentations, where the magnitude of the effect size is small and the direction is negative (an inverse relationship). Thus, students perceive that there exists an inverse relationship between facultys' use of a variety of technological tools, and use of group presentations, and, students' learning/success expressed in terms of their GPA. Students in the technology domain rely mainly on professors' lectures and laboratory works as the main modes of learning and any attempt by professors to use computer simulations, internet and videos may be perceived by some students as waste of time rather than learning.

\section{Association Between the Students' Perception of the Importance of Faculty Commitment to Student Success and Self-reported Learning/Success}

Question 4: Are there associations between students' perception of the importance of faculty commitment to student success [in terms of dedication to students, high expectations of students, being approachable by students, encouraging student accomplishment, and concern for student success] and student's self-reported success/learning (expressed in terms of self-reported technical competency and GPA), as perceived by seniors in the EET program?

The Pearson correlation coefficients for the relationship between faculty commitment to student success and students' perceptions of learning/success expressed in terms of their self-reported technical competency revealed small to medium effect sizes. 
However, the following relationships between the faculty commitment sub-constructs and self-reported technical competency reveal positive significant associations with medium sized effects.

a. High expectations of students, and summated FCSS are related to selfreported technical competency (Critical thinking).

b. High expectations of students, encouraging student accomplishment, concern for student success, and summated FCSS are related to self-reported technical competency (Job preparation).

c. High expectations of students, encouraging student accomplishment, concern for student success, and summated FCSS are related to self-reported technical competency (Job preparation).

d. High expectations of students, encouraging student accomplishment, concern for student success, and summated FCSS are related to self-reported technical competency.

These findings indicate that students perceive that faculty members' high expectations of students, encouraging student accomplishment and concern for student success are important for their learning and success. The findings also agree with Chickering and Gamson's [14] research-based principles of effective undergraduate education. They proposed that good practice in undergraduate education (1) encourages contacts between faculty and students, (2) develops reciprocity and cooperation among students, (3) uses active learning techniques, (4) provides prompt feedback, (5) emphasizes time on task, (6) communicates high expectations, and (7) respects diverse talents and ways of learning. These results also support the findings of Guskey [13] that effective teachers have positive regard for their students.

Once again, the fourth predictor of student learning/success, GPA, failed to yield any significant relationship with sub-constructs of faculty commitment with student, except for the sub-construct of high expectations of students where the value $(r=0.13)$ indicates a small effect size. This indicates that students who rate themselves high on technical competency perceive that faculty commitment in terms of high expectations of students is more related to student learning/success in terms of student GPA.

\section{Inter-correlations for Faculty Dimensions of Technical Currency, Teaching Techniques, Commitment to Student Success, an, Students' Self-reported Technical Competency}

Question 5: Is there a combination of the factors of faculty technical currency, faculty teaching techniques, and faculty commitment to student success, that predict selfreported student learning/success better than one alone, as perceived by seniors in the EET program?

The correlation analyses revealed significant relationships between the faculty technical currency and faculty teaching techniques $(r=0.61$, large effect size), and 
between faculty technical currency and faculty commitment to student success $(r=0.51$, large effect size).

Multiple regression analyses revealed that the multiple correlation coefficient $(R)$, using all the predictor variables simultaneously, is 0.42 , and the adjusted $R$ square is 0.166 , which indicates that $16.6 \%$ of the variance in student learning/success can be predicted from the three independent variables (faculty technical currency, faculty teaching techniques, and faculty commitment to student success) combined. The $R$-value of 0.42 indicates a medium to large effect size.

\section{Recommendations/Implications for Practice}

The study revealed that a majority of EET senior ( $90 \%$ or more) perceive that the most important factors that contributed to their learning and success are: coordinating laboratory with the lecture, up-to-date technical knowledge, organization and preparation of class and laboratory activities, and professors' lectures.

In the domains of engineering technology, to narrow the gap between the state-ofcurricula and state-of- technology in the industry, faculty are required to revise curricula frequently and maintain their technical currency. To improve student learning/success they should also be required to learn the pedagogy. This endeavor is very challenging, and requires institutional vision, planning, and allocation of appropriate resources. The following recommendations need to be implemented at the personal, program/departmental, and institutional levels to improve student learning/success by enhancing faculty technical currency and pedagogy.

1. At the personal level: Faculty members should do a yearly self-inventory of their technical currency, teaching techniques, commitment to student success, and should identify areas of improvement and pursue professional development activities to enhance their technical currency and pedagogical skills, and the do a self-assessment of their skills.

2. At the program/department level:

a. Administrators/chairpersons need to realize the importance of technical currency and pedagogy. Moreover, they should provide training opportunities for faculty to enhance their technical currency and strengthen pedagogy in order to improve student learning/ success. Appropriate funds should be allocated.

a. Curriculum development and revision activities should be synchronized with faculty development and training activities vis a vis technical currency and pedagogical skills, in order to optimize teaching/learning using continuous quality improvement (CQI).

4. At the Institutional/Organizational level:

a. Because of the applications orientation of engineering technology programs, faculty technical currency and faculty teaching techniques are essential to make student learning more relevant. Therefore, there is a need to formulate/revise institutional polices to encourage faculty to maintain technical currency and 
enhance their teaching techniques. Recognizing the need for change, and then changing, is very challenging and requires visionary leadership to formulate goal-oriented short-term and long-term policies, competent educators to implement policies, and the allocation of adequate financial resources that will ensure the success of these policies.

b. Presently accreditation bodies emphasize the importance of technical currency in their accreditation criteria, but no specific definition of the construct of technical currency exits. Accreditation bodies need to develop a blueprint for defining and assessing faculty technical currency so that program evaluators, school administrators and faculty can have a better understanding of the construct and its assessment. Furthermore the accrediting bodies should also emphasize the importance of pedagogical training.

\section{REFERENCES}

[1] Smerdon, E. T. (1996, December). It takes a lifetime. ASEE Prism, 56.

[2] Khan, A., Karim, A., Gloeckner, G., \& Morgan, G. (2004). Faculty technical Currency: Status report on a national survey of engineering technology faculty. Paper presented at 2004 ASEE Annual Conference, June 20-23, Salt Lake City, UT, and published in the conference proceedings.

[3] Bean, J. (1980). Dropout and turnover: The synthesis and test of a causal model of Student attrition. Review of Educational Research, 12, 485-540.

[4] Cambino, R. L., Denny, G. S., \& DeVore, J. B. (2000). College student retention at a midwestern university. Journal of College Admission, 22-29.

[5] Camara, W. J., \& Echternacht, G. (2000). The SAT and high school grades in predicting success in college. The College Board: Office of Research and Development, New York: 9

[6] Dyer, J. E., Lacey, R., \& Osborne, E. W. (1996). Attitudes of University of Illinois College of Agriculture freshmen toward agriculture. Journal of Agricultural Education, 37(3), 43-51.

[7] Lam, P., Doverspike, D., \& Mawasha, R. (July, 1999). Predicting success in a minority engineering program. Journal of Engineering Education, 265-267.

[8] Rodriguez, N. (1996). Predicting the academic success of Mexican American and White college students. Hispanic Journal of Behavioral Sciences, 18 (3), 329-342.

[9] Pascarella, E. (1980). Student-faculty informal contact and college outcomes. Review of Educational Research, 50, 545-595.

[10] Spady, W. (1971). Dropouts from higher education: Toward an empirical model. Interchange, 2(3), 38-62. 
[11] Tinto, V. (1982). Defining dropout: A matter of perspective. In Ernest T. Pascarella (Ed.) Studying student attrition (pp. 3-15). San Francisco, CA: JosseyBass.

[12] Accreditation Board for Engineering and Technology (ABET). (2002). 2003-2004 Criteria for accrediting engineering technology programs. Baltimore, MD.

[13] Guskey, T. (1988). Improving student learning in college classrooms. Springfield, IL: Charles Thomas Publisher.

[14] Chickering, A. W., \& Gamson, Z. F. (1987). Seven principles for good practice in undergraduate education. AAHE Bulletin, 39(7), 3-7.

[15] Knowles, M. S. (1980). The modern practice of adult education: From pedagogy toandrogogy. Englewood Cliffs, NJ: Cambridge Adult Education.

[16] Caine, R. N., \& Caine, G. (1991). Making connections: Teaching and the human brain. Alexandria, VA: Association for Supervision and Curriculum Development.

[17] Cohen, J. (1988). Statistical power and analysis for the behavioral sciences $\left(2^{\text {nd }}\right.$ edition). Hillsdale, NJ: Lawrence Erlbaum Associates.

[18] Bloom, Benjamin. (Ed.). (1956). Taxonomy of educational objectives: The classification of educational goals. New York: McKay.

\section{Appendix A}

\section{Student Survey}

Consider your technical professors' influence on your learning and success. Your input is needed regarding various aspects of these professors' technical currency, teaching techniques, and commitment to student success, and how these factors influenced your learning and success. Please indicate the extent to which you agree or disagree with the following statements (Questions 1-23) about your professors' influence on your learning and success using the following rating scale.

$1=$ This was not at all important for my learning/success, I strongly disagree (SD)

$2=$ I disagree with this statement (D)

$3=$ I moderately disagree with this statement (MD)

$4=$ I neither agree nor disagree with this statement $(\mathrm{N})$

$5=$ I moderately agree with this statement (MA)

$6=\mathrm{I}$ agree with this statement (A)

$7=$ This was very important for my learning/success, I strongly agree (SA) 
Please circle the appropriate number.

\begin{tabular}{|c|c|c|c|c|c|c|c|}
\hline & SD & D & MD & $\mathrm{N}$ & MA & A & $\mathrm{SA}$ \\
\hline $\begin{array}{l}\text { 1. My learning/success is due to my professors being current in } \\
\text { terms of subject matter (up-to-date technical knowledge). }\end{array}$ & 1 & 2 & 3 & 4 & 5 & 6 & 7 \\
\hline $\begin{array}{l}\text { 2. My learning/success is due to my professors being current in } \\
\text { terms of computer hardware skills. }\end{array}$ & 1 & 2 & 3 & 4 & 5 & 6 & 7 \\
\hline $\begin{array}{l}\text { 3. My learning/success is due to my professors being current in } \\
\text { terms of computer software skills. }\end{array}$ & 1 & 2 & 3 & 4 & 5 & 6 & 7 \\
\hline $\begin{array}{l}\text { 4. My learning/success is due to my professors being current in } \\
\text { new and emerging technologies. }\end{array}$ & 1 & 2 & 3 & 4 & 5 & 6 & 7 \\
\hline $\begin{array}{l}\text { 5. My success/learning is due to my professors being current in } \\
\text { terms of publishing technical papers and textbooks. }\end{array}$ & 1 & 2 & 3 & 4 & 5 & 6 & 7 \\
\hline \multirow{2}{*}{$\begin{array}{l}\text { 6. My learning/success is due to my professors being current in } \\
\text { terms of participating in technical seminars, workshops, } \\
\text { conferences, and professional organization activities. }\end{array}$} & 1 & 2 & 3 & 4 & 5 & 6 & 7 \\
\hline & SD & $\mathrm{D}$ & MD & $\mathrm{N}$ & MA & $\mathrm{A}$ & $\mathrm{SA}$ \\
\hline 7. My learning/success is due to my professors' lectures. & 1 & 2 & 3 & 4 & 5 & 6 & 7 \\
\hline $\begin{array}{l}\text { 8. My learning/success is due to my professors' use of a variety of } \\
\text { technological teaching tools (e.g. computer simulation, internet, } \\
\text { and videos). }\end{array}$ & 1 & 2 & 3 & 4 & 5 & 6 & 7 \\
\hline $\begin{array}{l}\text { 9. My learning/success is due to my professors' use of PowerPoint } \\
\text { to deliver lectures. }\end{array}$ & 1 & 2 & 3 & 4 & 5 & 6 & 7 \\
\hline $\begin{array}{l}\text { 10. My learning/success is due to my professors' use of a variety } \\
\text { of teaching strategies (e.g. individual work, discussions as well as } \\
\text { lecture). }\end{array}$ & 1 & 2 & 3 & 4 & 5 & 6 & 7 \\
\hline $\begin{array}{l}\text { 11. My learning/success is due to my professors' use of group } \\
\text { presentations. }\end{array}$ & 1 & 2 & 3 & 4 & 5 & 6 & 7 \\
\hline $\begin{array}{l}\text { 12. My learning/success is due to my professors' coordinating } \\
\text { laboratory work (experiments and projects) with theoretical } \\
\text { concepts covered in lecture. }\end{array}$ & 1 & 2 & 3 & 4 & 5 & 6 & 7 \\
\hline $\begin{array}{l}\text { 13. My learning/success is due to my professors' organization and } \\
\text { preparation of class and laboratory activities. }\end{array}$ & 1 & 2 & 3 & 4 & 5 & 6 & 7 \\
\hline $\begin{array}{l}\text { 14. My learning/success is due to my professors' use of individual } \\
\text { laboratory projects. }\end{array}$ & 1 & 2 & 3 & 4 & 5 & 6 & 7 \\
\hline \multirow{2}{*}{$\begin{array}{l}\text { 15. My learning/success is due my professors' timely feedback on } \\
\text { class and laboratory projects. }\end{array}$} & 1 & 2 & 3 & 4 & 5 & 6 & 7 \\
\hline & SD & $\mathrm{D}$ & MD & $\mathrm{N}$ & MA & $\mathrm{A}$ & $\mathrm{SA}$ \\
\hline $\begin{array}{l}\text { 16. My learning/success is due to my professors' dedication to } \\
\text { their students. }\end{array}$ & 1 & 2 & 3 & 4 & 5 & 6 & 7 \\
\hline $\begin{array}{l}\text { 17. My learning/success is due to my professors' high } \\
\text { expectations. }\end{array}$ & 1 & 2 & 3 & 4 & 5 & 6 & 7 \\
\hline $\begin{array}{l}\text { 18. My learning/success is due to my professors being } \\
\text { approachable. }\end{array}$ & 1 & 2 & 3 & 4 & 5 & 6 & 7 \\
\hline $\begin{array}{l}\text { 19. My learning/success is due to my professors' encouragement } \\
\text { towards my accomplishments in class and laboratory. }\end{array}$ & 1 & 2 & 3 & 4 & 5 & 6 & 7 \\
\hline $\begin{array}{l}\text { 20. My learning/success is due to my professors' concern for my } \\
\text { success. }\end{array}$ & 1 & 2 & 3 & 4 & 5 & 6 & 7 \\
\hline Students self-perception of competency & SD & $\mathrm{D}$ & MD & $\mathrm{N}$ & MA & A & $\mathrm{SA}$ \\
\hline $\begin{array}{l}\text { 21. Given a technical challenge, I can analyze a problem by } \\
\text { thinking critically. }\end{array}$ & 1 & 2 & 3 & 4 & 5 & 6 & 7 \\
\hline $\begin{array}{l}\text { 22. I have confidence in my knowledge of electronics engineering } \\
\text { technology (EET). }\end{array}$ & 1 & 2 & 3 & 4 & 5 & 6 & 7 \\
\hline $\begin{array}{l}\text { 23. Given a technical problem or specifications for a system } \\
\text { design, I can propose a solution by designing the necessary sub- }\end{array}$ & 1 & 2 & 3 & 4 & 5 & 6 & 7 \\
\hline
\end{tabular}




system/circuits and by constructing a prototype of the system.
24. What is your GPA?

25. Do you have any job offers presently? $\square$ Yes $\square$ No

If you answered yes, how many job offers do you have? \# of job offers $=$

26. If you have a job offer, what is the highest salary offered to you?

Highest salary offered $=\$$

27. Are you working presently? $\square$ Yes $\square$ No

If you answered yes, how many hours a week do you work? \# of hours/Week =

28. Gender $\quad \square$ Male $\square$ Female

29. Age Age $=\ldots$ years

30. Ethnicity/Race $\square$ Hispanic $\square$ Asian/Pacific Islander $\square$ African American $\square$ Caucasian

$\square$ American Indian / Alaskan Native $\square$ I do not want to provide this information

31. Are you a student member of any national professional/honor societies? $\quad \square$ Yes $\quad \square$ No

If you answered yes, which societies do you belong to? (Check all that apply)

$\square$ IEEE $\square$ ISA $\square$ Alpha Sigma Lambda $\square$ Chi Epsilon Delta $\square$ Epsilon Delta Phi $\square$ Phi Theta Kappa $\square$ Other 